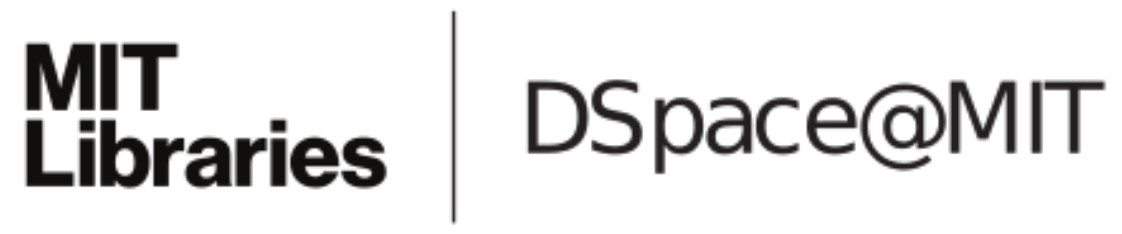

\author{
MIT Open Access Articles
}

\section{Combining Social, Environmental and Design Models to Support the Sustainable Development Goals}

The MIT Faculty has made this article openly available. Please share how this access benefits you. Your story matters.

Citation: Reid, Jack, Cynthis Zeng and Danielle Wood. "Combining Social, Environmental and Design Models to Support the Sustainable Development Goals." In 2019 IEEE Aerospace Conference, 2-9 March 2019.

As Published: 10.1109/aero.2019.8741623

\section{Publisher: IEEE}

Persistent URL: https://hdl.handle.net/1721.1/121527

Version: Author's final manuscript: final author's manuscript post peer review, without publisher's formatting or copy editing

Terms of use: Creative Commons Attribution-Noncommercial-Share Alike 


\title{
Combining Social, Environmental and Design Models to Support the Sustainable Development Goals
}

\author{
Jack Reid \\ Massachusetts Institute of Technology \\ 77 Massachusetts Ave. \\ Cambridge, MA 02139 \\ jackreid@mit.edu
}

\author{
Cynthia Zeng \\ Massachusetts Institute of Technology \\ 77 Massachusetts Ave. \\ Cambridge, MA 02139 \\ cynthia.zeng@outlook.com
}

\author{
Danielle Wood \\ Massachusetts Institute of Technology \\ 77 Massachusetts Ave. \\ Cambridge, MA 02139 \\ drwood@media.mit.edu
}

\begin{abstract}
There are benefits to be gained from combining the strengths of modeling frameworks that capture social, environmental and design-based considerations. Many of the important challenges of the next decade lie at the intersection of the natural environment, human decision making and the design of space technology to inform decision making. There are 17 Sustainable Development Goals outlined by the United Nations through 2030. Several of these Sustainable Development Goals can be addressed by asking: 1) What is happening in the natural environment? 2) How will humans be impacted by what is happening in the natural environment? 3) What decisions are humans making in response to environmental factors and why? and 4) What technology system can be designed to provide high quality information that supports human decision making? The answers to these questions are often interrelated in complex ways; thus it is helpful to use a framework from complex systems to integrate these questions. Within the list of Sustainable Development Goals, several fit the three questions above, including \#2 Zero Hunger, \#6 Clean Water and Sanitation, \#13 Climate Action, \#14 Life Below Water, and \#15 Life on Land.
\end{abstract}

This paper presents a research agenda to apply environmental modeling, complex systems modeling, and model-based systems engineering to inform the design of space systems in support of the Sustainable Development Goals. This work builds on previous research in the following areas: 1) physics-based environmental modeling; 2) complex systems modeling to simulate human decision making using agent-based models; and 3) model based systems engineering to inform the architecture of satellites or space-enabled data systems. This paper presents a review of the state of the art, shows examples of how these methods have been combined to inform space system design and presents a future research agenda. As an example, the paper discusses a project related to Sustainable Development Goal \#15 to design an earth observation system using spacebased and ground-based data collection regarding an invasive plant species in Benin, West Africa. In this example, insights are needed regarding natural variables (i.e. salinity, temperature and turbidity of local waterways), social variables (i.e. economic impact of the invasive plant on local communities), and design variables (i.e. the technical performance of existing imagery satellites and in-situ sensor networks).

\section{TABle of Contents}

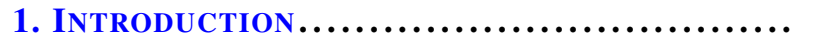

2. Sustainable Development \& Remote

SENSING .............................. 1

3. INTEGRATED MODELS $. . \ldots \ldots \ldots \ldots \ldots \ldots \ldots . \ldots$

978-1-5386-6854-2/19/\$31.00 (c)2019 IEEE
4. WATER Hyacinth in Benin Application ..... 6

5. MAngrove Forests in Rio de JANEIro ..... 8

6. MOVING FORWARD ....................... 9

ACKNOWLEDGMENTS ........................ 9

REFERENCES $\ldots \ldots \ldots \ldots \ldots \ldots \ldots \ldots \ldots \ldots \ldots \ldots, 10$

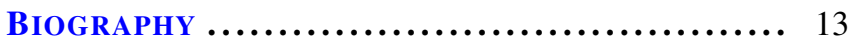

\section{INTRODUCTION}

Remote observation systems, both space-based and aerial, have seen significant increases in both number and quality over the recent decades. Data from these systems is also increasingly available, both as existing systems become free to access and as commercial entities launch their own platforms. This explosion in data, coupled with advances in machine vision, have enabled new, more detailed applications of remote sensing data, including those beyond the traditional military and scientific domains. With the recent coalescing of international priorities around the United Nations (UN) Sustainable Development Goals (SDGs), there is an opportunity to apply remote observation to benefit numerous communities around the globe. In order to fully take advantage of this opportunity, both in translating the data into real benefits and in designing new satellites to address these applications, better models of complex sociotechnical systems will be needed. This paper examines first what is meant by sustainable development and existing uses of remote observation to these ends. It then discusses existing models and the promise of integrated, complex systems models to enable future applications, before closing with an examination of two particular application cases currently underway.

\section{Sustainable Development \& Remote SENSING}

What do we mean by sustainable development?

Sustainability first enters engineering literature in the 1970's and its frequency rises in a logarithmic fashion over the course of the subsequent decades [1]. This rise is mirrored by a similar rise in other domains (such as architecture) and in the popular consciousness. For example, the Leadership in Energy and Environmental Design (LEED) certification program was founded in 1994 and has since become commonplace around the world. While the word "sustainability" is commonly used purely in a sense of "environmentally friendly," sustainability has been linked to development al- 
most from the beginning. The International Union for the conservation of Nature coined the phrase in 1980 [2] and the UN adopted it in 1987 in the Our Common Future report (commonly known as the Bruntland Report), where it was defined as "development that meets the needs of the present without compromising the ability of future generations to meet their own needs" [3]. Note that this definition extends beyond preservation or conservation of the environment to also include the needs of humans. Computational models have been closely linked to the pursuit of sustainable development and with its definition, stemming from the World3 system dynamics model underlying the Club of Rome's The Limits to Growth report in 1972 [4]. Over time, as our society has had both successes and failures in its pursuit of sustainable development, the specific goals and the means of pursuing them have changed. Consistent throughout the entire endeavor, however, is the same basic definition and the integral role that models continue to play.

In 2000, the UN established eight Millennium Development Goals (MDGs) that the nations of the world pledged to pursue for the next fifteen years. These were [emphasis added]:

1. To eradicate extreme poverty and hunger

2. To achieve universal primary education

3 . To promote gender equality and empower women

4. To reduce child mortality

5. To improve maternal health

6. To combat HIV/AIDS, malaria, and other diseases

7. To ensure environmental sustainability

8. To develop a global partnership for development

Within each of these goals were various more specific targets, each with a set of quantitative metrics or indicators. While significant progress towards the MDGs was made over the course of those fifteen years, significant issues persisted after their conclusion [5]. By the year 2015, numerous changes had occurred. There was an increased interest in recognizing the interdependence of the challenges facing humanity, treating causes rather than symptoms, and in collective action rather than donor-driven action. The MDGs, for instance, often focused exclusively on developing countries and what developed countries could offer them, sometimes explicitly so, such as in Target 8.E: "In cooperation with pharmaceutical companies, provide access to affordable essential drugs in developing countries." By the year 2015, there was an heightened recognition of disparities and issues within all nations, not just the developing ones. These factors, coupled with the rise in public salience regarding sustainability, resulted in the successors to the MDGs, the Sustainable Development Goals. The SDGs were set in 2015 and are intended to serve as global goals for the international community until 2030. It expanded the number of goals from 8 to 17 , each with its own set of indicators and targets [6]. Some of the original MDGs were split into multiple, more specific goals (e.g. \#1 became \#2 and \#3) while other SDGs are wholly novel. The abbreviated forms of these new goals can be seen in Figure 1.

The heightened importance of sustainability is evident both in the elevation of the word to the collective title of the SDGs, but also in the increased frequency of its use within the goals. In the original MDGs the word "sustainable" or a variant thereof is used only once in the goals and 6 times among the targets and indicators (and even then it is most commonly in reference to "debt sustainability"). In the SDGs, "sustainable" and its variants is found 13 times in the goals and 68 times among the targets and indicators, referring to a whole host of domains but most commonly referring to "sustainable

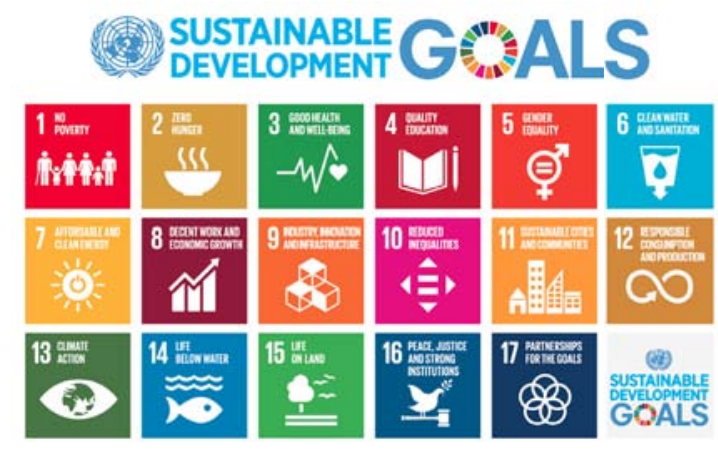

Figure 1. United Nations Sustainable Development Goals

development" or sustainable use of various resources.

Despite their short, clear formulations, actually achieving many of the SDGs involves the significant work by numerous actors in many domains and involving various technologies, as evidenced by the total of 169 targets and 232 indicators within the goals [7]. In short, they require either the creation or the improvement of complex sociotechnical systems. SDGs \#2 Zero Hunger, \#6 Clean Water and Sanitation, \#13 Climate Action, \#14 Life Below Water, and \#15 Life on Land in particular can be approached via four questions:

1. What is happening in the natural environment?

2. How will humans be impacted by what is happening in the natural environment?

3. What decisions are humans making in response to environmental factors and why?

4. What technology system can be designed to provide high quality information that supports human decision making?

Within SDG \#2, for instance is Target 2.3: "By 2030, double the agricultural productivity and incomes of small-scale food producers, in particular women, indigenous peoples, family farmers, pastoralists and fishers, including through secure and equal access to land, other productive resources and inputs, knowledge, financial services, markets and opportunities for value addition and non-farm employment." Associated with this target are indicators 2.3.1, "Volume of production per labour unit by classes of farming/pastoral/forestry enterprise size," and 2.3.2, "Average income of small-scale food producers, by sex and indigenous status." [7] Clearly, accomplishing this goal will require innovation in agricultural technology, creation of new policy and technological mechanisms for linking financial services to these small-scale food producers, and new methods of collecting information to enable both the evaluation of our progress and the sociotechnical systems created to reach the target.

\section{Remote sensing to inform sustainable development}

While many of the initial efforts at remote observation from air and space were done with military objectives in mind, scientific, commercial, and social applications soon became abundant. Since space-based remote observation in particular was primarily driven by large governmental scientific organizations, much of that data was made publicly accessible. This has continued to the present day. An enormous amount of earth observation (EO) satellite data is freely available to the public through 20+ National Aeronautics and Space Administration (NASA) earth science satellites [8], the European Space Agency (ESA) Copernicus Programme 
(which includes both the 6 Sentinel satellites and in-situ measurements), the various satellites managed by the Japan Aerospace Exploration Agency (JAXA) Earth Observation Center (EOC), the China-Brazil Earth Resources Satellite Program (CBERS), and the satellites of other space agencies. While this data is largely free currently, this has not consistently been true, nor is it guaranteed to continue in the future [9]. Various countries have shifted back and forth between attempting to monetize remote observation data and making it freely available. This is true both for potential future missions and existing platforms. Landsat data, for instance, is currently freely available after a long, troubled history of commercialization [10], but may not remain so moving forward [11].

The rise of multiple EO satellite companies, including the company Planet's 100+ satellites [12], Digital Global's WorldView satellites, and Astro Digital's recent launch of their first two satellites [13], suggests that yet more satellite data is soon to be available for a price. These data sources are likely to be complimentary, with the commercial satellites primarily providing visual imagery and NASA satellites primarily supplying other forms of scientific data, though the Moderate Resolution Imaging Spectroradiometer (MODIS), the Visible Infrared Imaging Radiometer Suite (VIIRS), and the Landsat program all capture visual imagery as well. While many of these satellites were designed primarily with scientific purposes in mind, this data is increasingly being used by a wide variety of groups around the world to enable sustainable development and other humanitarian applications, such as forest fire tracking [via MODIS and VIIRS [14]], agricultural monitoring [via Global Precipitation Measurement (GPM) for rainfall [15] and GRACE for soil moisture [16]], climate change vulnerability assessments [via Ice, Cloud, and land Elevation Satellite 2 (ICESat-2) for vegetation and ice monitoring [17]], and many other applications, such as the upcoming Surface Water Ocean Topography (SWOT) [18].

Over the course of the past two decades, efforts have been made to systematize the application of remote sensing data to inform decision-making on a host of sustainable development areas. Internationally, over 100 countries worked together to form Group of Earth Observations (GEO) and 60 agencies with active earth observation satellites have formed the Committee on Earth Observation Satellites (CEOS). In the US, the primary source of such applications is the NASA Applied Science Program, a part of the Earth Science Division, that includes programs focused on disasters, ecological forecasting, health \& air quality, water resources, and wildland fires, using data from NASA satellites as well as those of the US Geological Survey (USGS) and the National Oceanic and Atmospheric Administration (NOAA). The Applied Science Program, through their Capacity Building portfolio, frequently partners with other organizations, such as United States Agency for International Development (USAID). For instance, both groups worked together to form the Sistema Regional De Visualización Y Monitoreo De Mesoamérica (SERVIR), which provides geospatial information and predictive models to parts of Africa and Asia. In a similar collaborative effort, NASA and USAID have also integrated remote sensing data into the Famine Early Warning Systems Network (FEWS NET). Such efforts have been quite successful in their goals, but have required significant time, expertise, and effort to create and maintain. As overpass frequencies, resolutions, and computational speed have increased, it is increasingly possible to conduct much more rapid, localized, and ad hoc applications of remote sensing data for sustainable development and humanitarian purposes. Within 48 hours and one week respectively, NASA was able to provide maps of damaged areas of Mexico City to Mexican authorities following the 2017 earthquake [19] and maps of damaged areas of Puerto Rico to the Federal Emergency Management Agency (FEMA) following Hurricane Maria [20] (in fact, both of these maps were provided during the same week), through NASA's Disasters Team under the Applied Sciences Program. Such data collection and processing can increasingly be done without the expertise and remote observation systems of governmental space agencies, as demonstrated by a recent effort to conduct near-real-time deforestation monitoring and response [21].

Increasingly, such applications are not limited by available remote observation platforms, but by lack of knowledge by potential end-users of its value and by the tools to make use of available data. While data is often available (either freely or at some cost), it is not always readily accessible (particularly in real time) or easily interpreted. This is a problem that multidisciplinary models are poised to solve.

\section{INTEgRATED MODELS}

Integrating physics and engineering models has a long history and has become commonplace in the aerospace industry via initiatives such as model-based systems engineering (MBSE) (languages such as SysML and UML and software such as IBM's Rhapsody, NoMagic's MagicDraw, and ViTech's GENESYS), multiphysics design tools (such as the Analytical Graphics, Inc. (AGI) Systems Tool Kit (STK) or Sandia National Labs' Albany and Peridigm), and concurrent engineering facilities (such as Team-X at the NASA Jet Propulsion Laboratory (JPL)). Applications span from fullscale aircraft design [22] to the design of injection molding systems [23]. As was predicted more than a decade ago [24], efforts to extend such model integration throughout the system development process and into the actual operational life of the system have surged ahead, as demonstrated by the Digital Thread [25] and Digital Twin [26] programs at both NASA and the US Department of Defense (DoD). Standards, such as IEEE's High-Level Architecture, have been developed and have found significant use, particular in aerospace and industry [27].

Integrating models from outside of physics and engineering has also made progress. Due perhaps to the numerous applications of remote observation for humanitarian and sustainable development applications discussed earlier, numerous attempts have been made at quantifying the value of various earth observation systems, but many of these were limited by the inherent difficulties of handling counterfactual scenarios [28]. NASA is well aware of this difficulty, which is why the Applied Sciences Program funded the Consortium for the Valuation of Applications Benefits Linked with Earth Science (VALUABLES) at the Resources for the Future (RFF). This consortium is using economic methods to improve estimates of the societal benefits of earth observation. Work by VALUABLES and others has quantified the value of remote observation systems for carbon emission tracking [29], agricultural production [30], and ground water quality [30]. The recent advances in this field are cataloged in the recent publication of a book on the socioeconomic value of geospatial information (which includes more than remote observation) [31]. Integrating econometric models with remote observation system models is useful for both assessing the impact of past missions and for predicting the impact of 
future ones. Such results can be used to help justify the field as a whole and specific remote observation systems in particular. Many applications, however, require more detailed models that integrate more domains. This is particularly true if the intent is to provide remote observation data to inform operational decision-making.

The Environment-Vulnerability-Decision-Technology framework for integrated modeling

The environment, societal impact, human decision-making, and technology are four domains with complex interactions. While significant benefit has come from addressing each individually in detail and yet more from considering certain groupings (such as the economic valuations that combine technology and societal impact), capturing all four together can enable us to overcome important challenges that lie at the intersections of these domains. Figure 2 shows a baseline modeling framework for an Environment-VulnerabilityDecision-Technology Model that seeks to inform human decision-making for sustainable development.

In this integrated model framework, each component (e.g. environmental, technology design, etc.) is referred to as $s u b-$ models. It should be noted that this is context dependent. That is, in other contexts, outside of this integrated framework, many of these submodels are stand-alone models, often quite detailed and sophisticated ones at that. The integrated model is a particular means for "tying" these together into one complex systems model. Below, the submodels are defined and examples given. Each of these submodels are well developed fields in their own right and an attempt to survey any one would be much longer than a single article. The examples are thus intended to be demonstrative, particularly of those relevant to the topic of this paper, not to be exhaustive.

Environmental Submodels-Environmental submodels seek to capture the behavior of natural phenomena, from weather patterns, to plant growth, to ice formation. Some, such as many of those used by the Intergovernmental Panel on Climate Change (IPCC) are global in scale, simulating the behavior of numerous interacting systems across the planet [32]. Others are much more local in scale, seeking to model particular locations for either scientific or policy purposes. These models vary immensely in computational method and focus as well. For example, as part the Mid-Atlantic Regional Integrated Sciences and Assessments (MARISA) program under NOAA, RAND Corporation researchers examined some 141 different models applicable to the Chesapeake Bay, each with different goals, sets of assumptions, and validation data. Specific models used in conjunction with remote sensing data include the Land Information System (LIS), the ADCIRC Circulation and Transport Models, and the USACE Coastal Storm Modeling System, to name just a few [33]. Such models have a rich history that predates computational models, as evidenced by the Mississippi River Basin Model Waterways Experiment Station [34].

Technology Design Submodels-Technology Design submodels seek to simulate engineered artifacts and assist in the design process. They are as commonplace and numerous as environmental submodels, and similarly predate computation [35]. Many, including both Autodesk's and Dassault Systemes' products, integrate computer-aided design (CAD) with simulations of structural, thermal, fluid, and electrical performance (among others). Some focus at the component level while others are intended for simulation of a full Concept of Operations time-line. In satellite design, the aforementioned AGI STK and Dassault Systemes' Solidworks are both widely used, though it is also quite common for both governmental space agencies and private organizations to develop their own in-house models.

Human Vulnerability \& Societal Impact Submodels-Human Vulnerability \& Societal Impact submodels seek to simulate and predict the degree of impact of some policy or phenomena on a set of people. They are perhaps most commonly seen in natural disaster response/relief and in economic policy-making. With regards to the former, such models are used for a variety of disaster types, from floods to wildfires to tsunamis, both by insurance companies to set rates [36] [37] and by governments to reduce vulnerability and to prepare for response efforts [38] [39]. These models vary immensely in computational methods, from dynamic simulations to parametric estimations. Unlike natural disaster vulnerability models, economic models simulate both positive and negative impacts. These models are commonly used by governmental organizations for setting national and international policy, and examples include the Congressional Budget Office's Microsimulation Tax Model [40] and the World Bank's Long Term Growth Model [41]. Such models are commonly parametric (the Long Term Growth Model is embodied by an Excel spreadsheet for instance), but there is a long history of using various kinds of dynamic models as well, particularly within the field of evolutionary economics [42].

Human Decision-Making Submodels-Human DecisionMaking submodels seek to simulate and predict the decisions made by an individual or a group of humans. Depending on the intended application, the computational method and underlying theory can vary immensely, from agent-based [43] to cellular automata (both of individuals in a crowd [44] and to en-masse urban development [45]) game-theoretic [46] [47] to combinations of multiple of these and others [48]. These models, perhaps more so than any of the other submodel types, pulls heavily from the social sciences, psychology and economics in particular.

Combinations of Submodels-As mentioned before, many examples linking certain submodels of this integrated model together already exist. In particular paired submodels are common. Technology Design and Environmental submodels are commonly considered together to improve system designs. Space agencies and the earth science community has significant experience with such combinations. Originally developed for operational weather forecasting, Observing System Simulation Experiments (OSSEs) have found widespread use for designing earth observation systems at NASA and elsewhere [49]. These models are rigorously validated [50] and are often custom-made for a particular mission. Significant progress has been made however by the Hydrological Sciences Laboratory and Earth Science Technology Office at NASA in developing the LIS, a more reusable and interoperable modeling tool with numerous earth sciences applications (soil moisture, hydrology, meteorology, etc.) [51]. One of these uses is the easier development of OSSEs, as a means of facilitating technological development. Since the development of the LIS, the Hydrological Sciences Laboratory has worked to make the earth science models more accurate, utilize a broader range of computational methods, and standardize the validation and evaluation processes for OSSEs. On the commercial side, while STK is chiefly a technology design submodel, it is frequently employed in conjunction with environmental submodels to improve the quality of system design. 


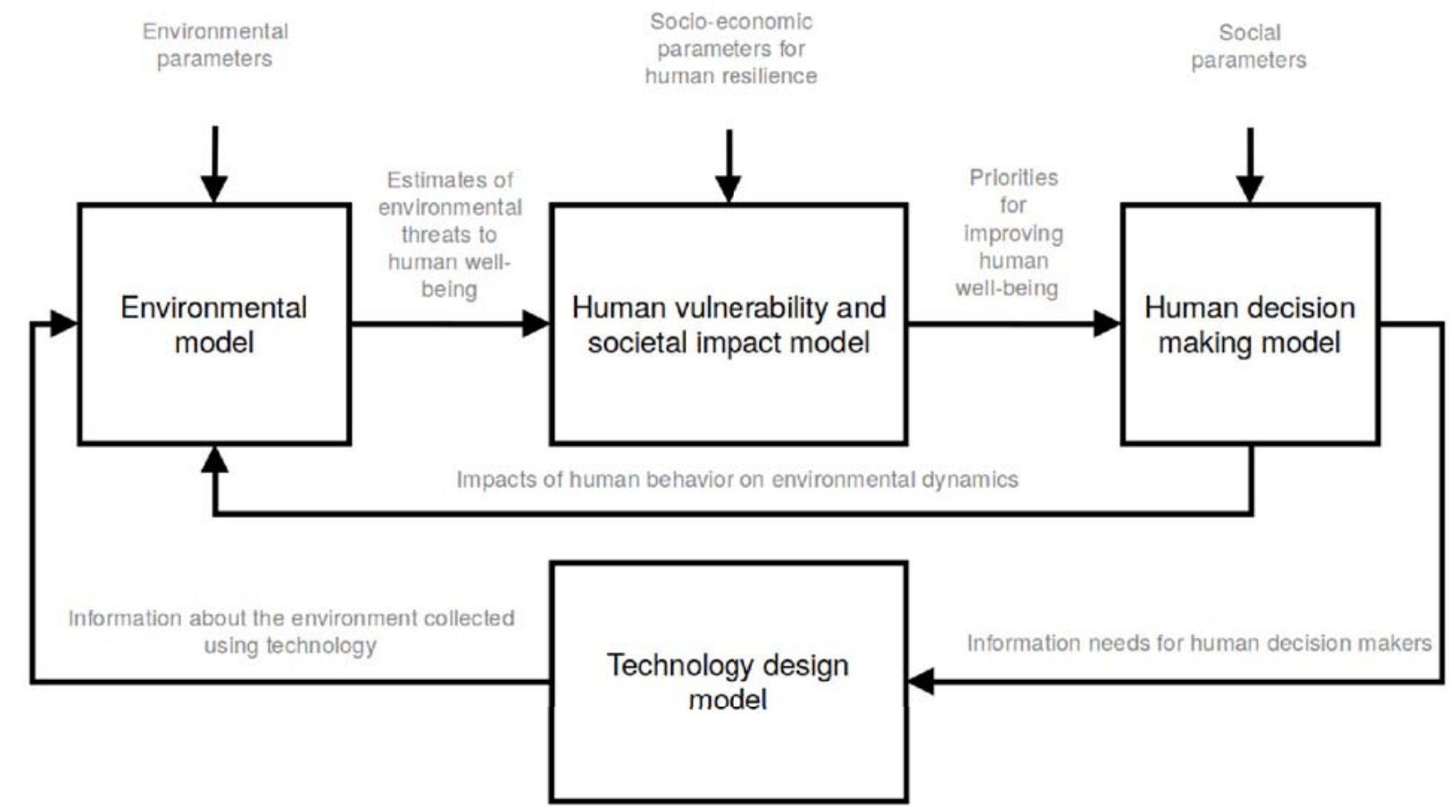

Figure 2. Baseline version of the Environment - Vulnerability - Decision - Technology Model (Generic Case)

Environmental and Vulnerability submodels are used in conjuction to prepare for natural disasters, floods, or other changes in the environment. Vulnerability and DecisionMaking submodels are frequently integrated in various economics and urban planning applications, to design effective incentives and policies to influence individuals towards a societal goal. Examples of this last include efforts to model consumer choice in electricity generation [52] or emission reduction decisions [53].

Some fields, particularly energy, have developed integrated models that take into account three of the submodels. ENERNET assumes a fixed sensing technology (WiFi) and seeks to capture the behavior of humans within buildings and determine the energy consumption of that building [54]. The TripEnergy model combines an environmental submodel (transportation systems) and societal impact submodel (energy consumption and emissions of vehicles) [55]. It is then combined with a model of human decision-making to create Tripod, "a smartphone-based system to influence individual real-time travel decisions by offering information and incentives to optimize system-wide energy performance" [56].

The aforementioned successes in linking various combinations of submodels together indicate that there is the potential for significant benefits to be had from integrated modeling. That said, none of the examples cited fully capture the framework shown in Figure 2. Even The TripEnergyTripod model was focused primarily on changing the human decision-making framework, rather than designing new sensing or transportation technologies, and it thus had only some of the feedback loops shown in Figure 2. There is still a need for models that can simultaneously answer each of the four questions proposed earlier. This is particularly true in domains where such answers are intrinsically tied to one another. Earth scientists would never consider designing a modern earth observation satellite without a functional model of the environment it will be observing. Similarly, there are many complex sociotechnical systems that require a holistic approach.

\section{The future of integrated modeling for sustainable develop-} ment

The Space Enabled Research Group at the MIT Media Lab is working to advance justice in Earth's complex systems using designs enabled by space. Space Enabled identifies six space technologies that are already used to support the UN SDGs, but whose impact is reduced due to the presence of certain barriers. The six technologies are satellite earth observation, satellite communication, satellite positioning, microgravity research, technology transfer, and inspiration gained via research and education. The Space Enabled team of researchers represent the fields of satellite engineering, design, art, social science, complex systems modeling, and data science. In particular, we believe that complex system modeling, by integrating the four modeling domains discussed earlier, can help unite these fields and provide answers to the questions posed earlier.

While the LIS environmental model is highly useful to the hydrological sciences, numerous other applications exist for current and future EO data. This includes fire tracking and other earth science domains that SERVIR and other NASA Applied Sciences Program initiatives have addressed, as well as areas like carbon emissions, the economic consequences of which groups such as VALUABLES are seeking to quantify. Beyond these there are more human-centric applications, such as monitoring traffic, urban development, mining, oil well production, agriculture, and fishing, to name just a few. While these applications could benefit from specifically targeted satellite imagery, there is potential for significant 
gains in understanding to be had from combining existing EO multispectral data with integrated complex systems models.

Not all potential applications have a dedicated technical organization with remote observation data expertise on hand. Due to a combination of a lack of awareness of the potential benefit of remote observation platforms and the lack of capability to make use of such platforms, many application cases have had to rely on substantial support of space agency experts. SERVIR, FEWS NET, Fire Information for Resource Management System (FIRMS), and many other applications would not have been possible without governmental space agency assistance (or outright ownership in the case of FIRMS). One proposed conceptualization of the EO application value chain has the eight steps shown in Figure 3 [33], [57]. Space agencies frequently find themselves not only providing steps 1-3 (their specialty) but also some combination of 4-8.

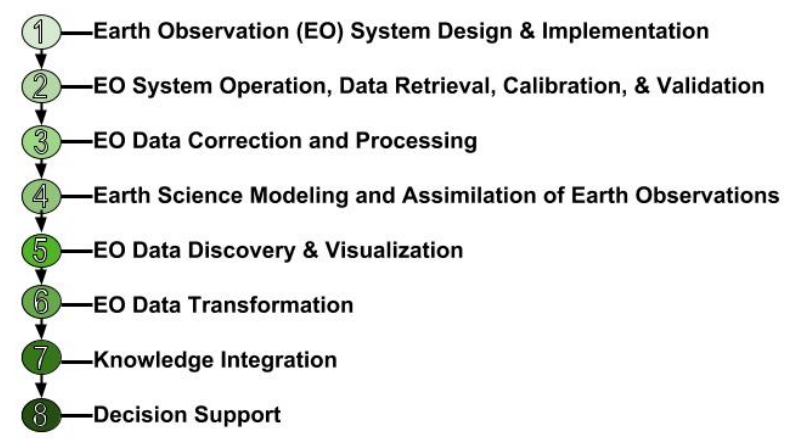

Figure 3. Generic Earth Observation Data Value Chain

While some of these steps, particularly on the latter half, are being addressed in certain contexts by private corporations (Digital Global's Penny tool cover most of these steps [57] and Planet increasingly does the same), there are still many applications, particularly sociotechnical ones, that remain untouched. Furthermore, all of the application platforms cited thus far focus on a single, existing remote observation platform. They do not enable ready integration of multiple imagery sources nor do they enable the end-user to explore hypothetical satellite designs that would better suit their needs than the extant systems.

Another method of approaching the application of remote sensing data to sustainable development is through the use of NASA's Application Readiness Levels (ARLs) [58]. The ARLs, which can be seen in Figure 4, are intended to mirror the more well known Technology Readiness Levels (TRLs). Under this metric, applications such as FEWS NET and SERVIR can be seen as fully developed ARL 9. Many other applications, which exist as proposals in academic research, are closer to ARL 3. The Benin Water Hyacinth case, discussed in the next section, has reached ARL 3 and work on the Phase II levels is underway.

Moving forward, what is needed are integrated models that "close the loop" of Figure 2, rather than selectively address linear combinations of certain submodels. Moreover, we argue that this need should not be addressed merely by the creation of individual case-specific models, but by the creation of a open-source modeling standard and library that enables the "swapping" of specific submodels within the EnvironmentVulnerability-Decision-Technology integrated model. Such

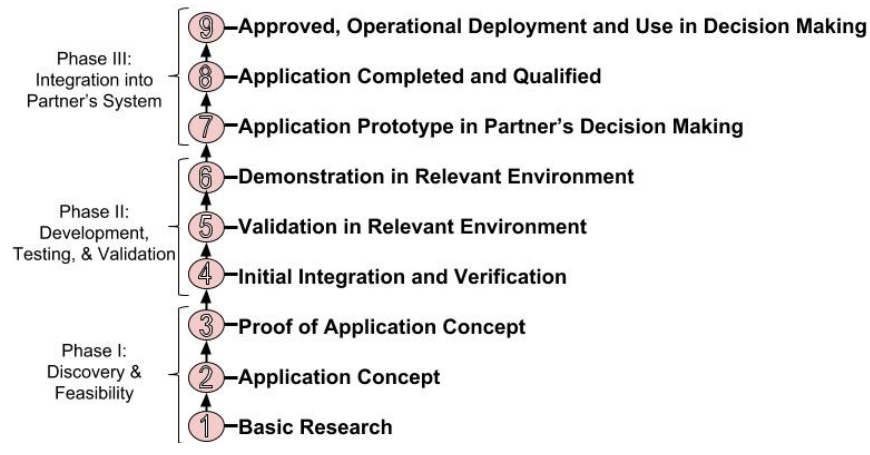

Figure 4. Applied Readiness Levels

a standard could very well make use of existing models. For instance, the Technology Design submodel such as STK could feed into the Environmental submodel such as LIS and in turn into the Vulnerability and Human Decision-Making submodels. Where existing submodels are incapable of such integration, new ones will have to be made, but they should only have to be made once. The construction of a library of submodels would enable communities and organizations with experience in only one or two of the submodel domains to readily assess what remote observation has to offer them. It would let them see what existing platforms exist and enable them to clearly specify any gaps in sensing capability. This would facilitate the process of quickly moving from the Phase I ARLs to Phase III ARLs with reduced outside assistance.

This is an effort that will take many years and involve researchers from many fields and institutions. Space Enabled is taking the first steps towards this goal however, in the development of an integrated model for several particular cases. The intention is to use these cases to identify existing models that are capable of integration, to determine how best to structure submodel interfaces, to evaluate the viability and scientific interest of this endeavor, and to assess the needs of the end-user communities. Two of these cases are discussed below.

\section{Water Hyacinth in Benin Application}

Eichhornia crassipes, more commonly known as water hyacinth, is an aquatic plant species native to the Amazon river basin. It has been spread by humans, however, to North America, Europe, Africa, and Asia; and is commonly regarded as an invasive pest plant. This reputation stems from its ability to aggressively spread and cover entire lakes and ponds, as well as substantially block rivers. During this process, it depletes oxygen in the water, provides habitats for mosquitoes and other parasites, and inhibits transportation, both human-powered (through resistance) and motorized (by clogging propellers and motors). These impacts have led to a wide variety of attempted methods of control, as well as various national and international bans on its sale and transport [59].

Benin is one such country impacted by the global spread of water hyacinth. In particular, Lake Nokoué (the largest body of water in the southern part of the country), the Ouémé River, and the Sô River, as well as the various waterways associated with these three, have seen significant growths of the plant. This is a heavily inhabited region of the country, as 3 of the 5 
largest cities in the country are either on or near Lake Nokoué (totaling to approximately 1.4 million of the country's 11.6 million people). 40,000 people live on the lake itself, in habitations built on stilts known as Ganvié villages [60]. The lake and rivers are heavily relied upon for transportation, fishing, and the harvesting of building materials, all of which are inhibited by the spread of water hyacinth.

The water hyacinth is not without its uses, however. A Beninese start-up, Green Keeper Africa, uses dried and ground hyacinth in the production of sorbents for controlling pollutant spills [61]. Green Keeper Africa pays local lake communities to harvest and dry the hyacinth. These communities are paid by mass collected and have discretion on the specific locations that they harvest the plant. While any harvesting benefits both the lake ecosystem and the humans who make use of it, it is likely that more selective targeting of harvesting efforts may produce an increased positive impact. To determine whether this is indeed the case and to improve the harvesting locations would require us to answer the first three of the proposed questions. Namely:

1. What is happening in the natural environment? Where is the hyacinth currently? Where is it likely to grow in the future? What factors (water temperature, salinity, seasons, etc.) impact its growth? How do these factors vary over time and location?

2. How will humans be impacted by what is happening in the natural environment? How are local community residents impacted by the presence of the water hyacinth in areas such access to employment, food, and clean water?

3. What decisions are humans making in response to environmental factors and why? How do local communities adapt to the growth of hyacinth? Would its removal benefit them? If so, where are the optimal locations for harvesting?

To address Question 1, we must make use of remote sensing technology. Identifying, mapping, and tracking water hyacinth through the use of remote observation systems has been done in both India [62] and California [63]. These previous cases have used both satellite-based and aircraft-based imagery in the visible and infrared spectrum. Small aircraft carrying HyMap (or similiar) sensors, space agency satellites such as LandSat and Sentinel, and private satellites such as Planet's Flock constellation are all potentially available for monitoring water hyacinth in the Lake Nokoué region. Work is currently underway at Space Enabled to make use of available data for mapping the water hyacinth in the Lake Nokoué region and validating these maps using on-the-ground and aerial data collection. The resolution, spectral sensitivity, and/or overpass rate of the available platforms may, however, prove insufficient to effectively answer Questions 1-3. If this is the case, we will turn to the fourth question proposed earlier:

4. What technology system can be designed to provide high quality information that supports human decision making? Specifically, what satellite, aerial, and water-based sensing platforms would prove sufficient to address this need?

Not only can an integrated Environment-VulnerabilityDecision-Technology model answer these questions, but it is necessary to answer these questions, due to how these questions are interconnected. The optimal harvesting locations cannot be identified without understanding the human systems and knowing where the hyacinth is. Similarly, the ideal satellite architecture cannot be determined without fully understanding the application that would serve. With all of this in mind, we can update the general model framework shown in Figure 2 to a specific one, as shown in Figure 5.

Work on this complex system model is currently underway on multiple fronts. Satellite earth observation imagery from Landsat, Sentinel, and Plant spacecraft are being used to understand current and historical patterns of water hyacinth blooms. Agent-based models of human activity and harvesting decision-making are also in progress. Water-based sensors have been prototyped and are being made more robust. The feasibility of aerial sensors is being actively explored.

This case is likely to both provide the initial modules for the more general library discussed earlier and to inform the submodel interface standards of the generalized framework. That said, every well-designed model has a specific set of goals that it is intended to address. In the Benin water hyacinth case, the proposed model has four particular goals.

Informing Harvesting location selection: Through knowing where the hyacinth is, where the hyacinth will grow, and how it impacts local communities, the harvesting strategy can be improved. In the current harvesting system, this would be done by selecting specific local communities based on their proximity to high priority hyacinth clusters.

New policy design: This model could also be used to explore entirely different harvesting schemes, including ones where Green Keeper Africa directly selects harvesting locations or where another entity, such as the Benin government, does the harvesting. Beyond harvesting, the Benin government or other organizations may desire to take other actions, including controlling urban waste that contributes to water hyacinth growth or changing human activity patterns on the lake to adapt to the presence of the hyacinth.

Harvesting impact estimation: Beyond improving the specific harvesting policy, the model could be used to determine total value generated by a particular harvesting strategy. This can be useful in proposals to local communities, governments, and development agencies for both the harvesting policy and for other interventions.

New satellite design: By integrating a satellite design module into the complex systems model, we can identify feasible architectures for improved sensing and decisionmaking. Once the value of water hyacinth harvesting has been quantified, these costs and benefits of these architectures can be evaluated in a tradespace. This is not only useful for selecting an architecture, but also for assembling the support needed to bring the satellite from concept to orbit. A key potential need in this case is an increased overpass rate. Water hyacinth drifts with the current and the presently available remote observation imagery refreshes at most once per day, it is possible that more frequent data will be needed to make effective decisions. This is exacerbated by the fact that equatorial regions, such as Benin, are rarely cloud free. Currently Planet has a daily overpass rate but is often stymied by cloud cover.

To accomplish these goals and fully instantiate the model, various tasks still need to be completed. Some of the most notable are the following:

- Detailed understanding of the human activity patterns in the Lake Nokoué region. This includes identification of transportation routes, community locations, and fishing activities.

- Better understanding and monitoring of the Lake Nokoué environmental factors that impact water hyacinth growth. In 


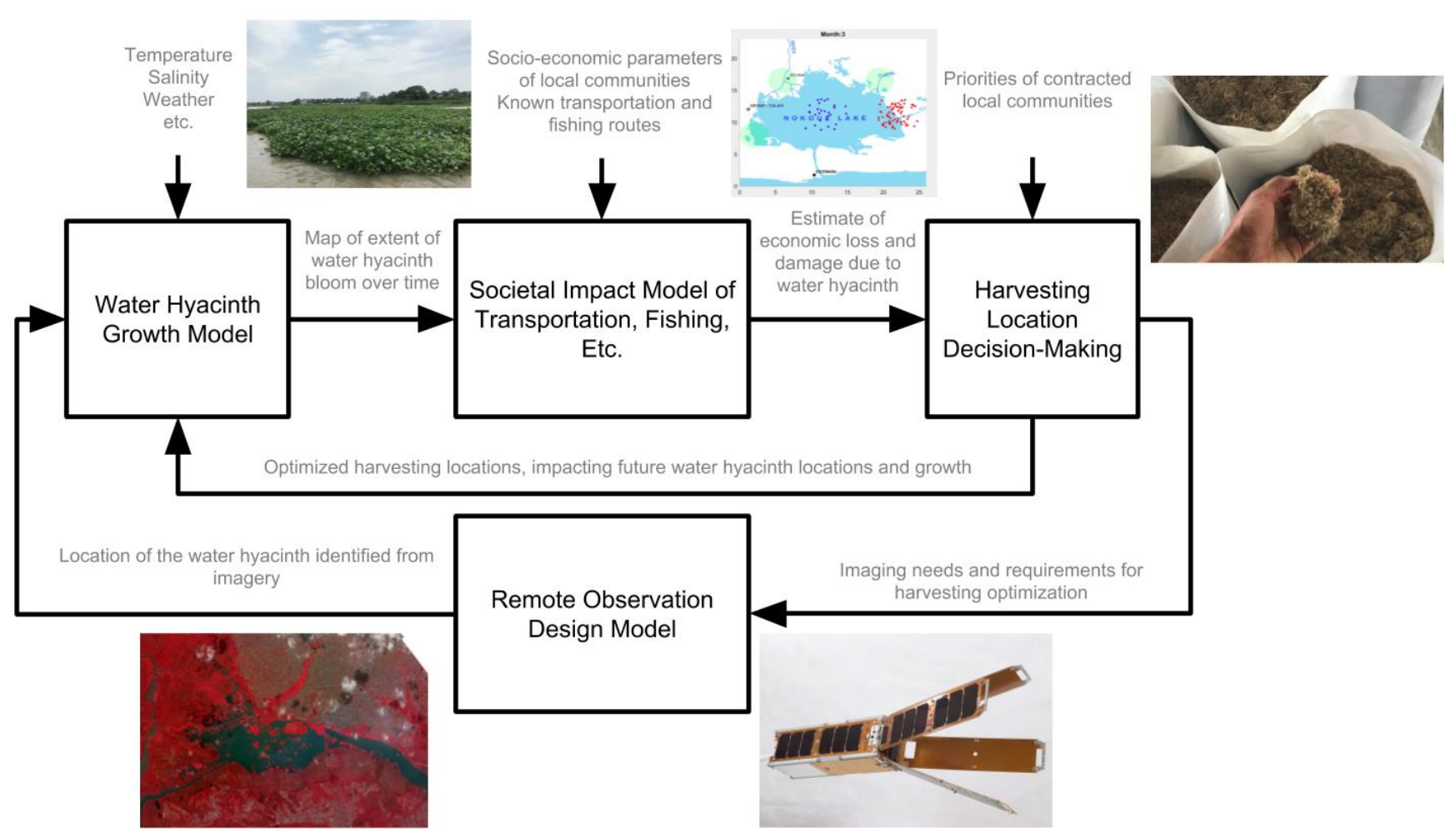

Figure 5. Environment - Vulnerability - Decision - Technology Model (Water Hyacinth Case)

particular salinity is known to have a significant role in water hyacinth growth and death. Due to Lake Nokoué's hydrology, the salinity value varies significantly over time. This process will need to be monitored and understood.

- More thorough and rigorous on-the-ground validation of remote observation water hyacinth identification. This includes both confirming the presence of plant matter at the identified locations and avoiding mis-identification of other non-hyacinth plant matter.

\section{Mangrove Forests in Rio de Janeiro}

The mangrove forest is a special type of forest which grows in between land and sea. They have many important ecological and environmental properties, such as stabilizing the shorelines [64] and providing a habitat for a wide range of species [65]. Although the total area of mangrove forests is not significant, their significance in maintaining a healthy coastal ecosystem is fundamental.

In Rio de Janeiro, mangrove forests in Planning Area 5 are highly vulnerable due to both landward urbanization pressure, including a recently opened urban transit line, and seaward pressure from rising sea levels. Therefore, a model to evaluate both environmental risks, such as rising sea levels, and social risks, such as land use conversion into urban or agricultural use, is needed to holistically understand questions related to the protection of mangrove forests in Rio de Janeiro. Returning to our four questions, we ask the following:

1. What is happening in the natural environment? What are the impacts of seal-level rise and urban expansion on the mangrove forests? What role do complex secondary factors such as sedimentation change due to land use conversion and organic discharge due to agricultural activities, play in determining mangrove growth?

2. How will humans be impacted by what is happening in the natural environment? What impact do the designation of natural reserves have on the community? What effects would the lack of mangroves have on the city? What is the value of the carbon sink of mangrove forests?

3. What decisions are humans making in response to environmental factors and why? How are planning policies such as restricted land use conversion in certain protected natural reserves developed? How are other centralized and decentralized decisions made, such as the rate of urban expansion or the development of transportation infrastructure?

4. What technology system can be designed to provide high quality information that supports human decision making? What satellite, aerial, and in-situ sensing platforms are needed by the Sistema Municipal de Informações Urbanas (SIURB) to accomplish their mission?

To address these questions, Space Enabled is working with researchers and urban planning officials in Rio de Janeiro's SIURB to develop a complex systems model to investigate how sea level rise and urban expansion together would impact the mangrove ecosystem and how these changes to mangrove forests in turn impact the city.

An integrated model is the only way to capture the wide variety of biological behaviors of mangrove forests that can occur in response to certain environmental changes. For instance, mangrove's response to rising sea levels depends on sedimentation level in shoreline areas[66], which can be altered due to human activities such as residential develop- 
ment [67]. Mangrove forests have a viviparous reproduction system with seeds that are buoyant and can remain dormant until being transported to a suitable environment by the waterways [68]. Therefore, the logic map underlying the integrated model must incorporate both the primary and the secondary factors linking together environmental and social factors. By capturing these linkages, the growth of mangrove forests can be simulated for scenarios that differ on a variety of factors, including the rate of mangrove reproduction, the sea level rise rate, and preference for proximity to transportation in residential and agricultural development.

Additionally, an integrated model could help evaluate current urban planning policies in Rio de Janeiro. Currently several regions within the natural reserve, i.e. a subset of total mangrove forests, are protected against any land use conversion. With such a model, new boundaries could be considered and other potential policies could be investigated, such as various urban expansion rates, various transportation infrastructure scenarios, and more sophisticated restriction policies on land use conversion.

With these questions and goals in mind, a specific instance of the integrated model framework can be represented as shown in Figure 6. In order to develop such a model, a number of steps remain to be completed. Some of the most notable include:

- Determination of certain parameters based on historical data. These include the rate of sea level rise and the rate of urban and agricultural expansion, both of which should be identifiable from a combination of satellite data and local in-situ measurements.

- Collection of various demographic and social data to improve risk estimation methods for the impact of the loss of mangroves. These include population data, urban land use types, and their differential impacts on local forests. For instance, some evidence suggests that particular residential land use types, such as favelas, may lead to more severe deforestation impacts [69].

- Better understanding of the civic decision making process in Rio de Janeiro. This is necessary in order to identify what urban development policies should be simulated using the integrated model.

\section{Moving Forward}

We have proposed a four part framework for integrated models to improve both the application of remote sensing data for sustainable development and the design of new remote sensing platforms. Many components of such an integrated model already exist. What is needed now is to combine these components and then to specify a submodel interface standard to enable the construction of libraries of submodels. Combining submodels in effective manner is a nontrivial process. Models from different disciplines often operate on different types of logic and under different conceptions of the world. While methods for reliably handling model interactions (a process commonly known as "handshaking") exist [70], they remain both empirically and epistimologically fraught [71]. Significant care will be needed in evaluating whether or not the integrated model is useful and in determining that it has acceptable levels of internal and external validity.

Regarding internal validity, this will be assessed using a combination of historical data and newly collected data from the case study environment. Efforts are currently underway to both identify and access such data, which, in the case of newly collected data will likely involve the deployment of additional in-situ sensors. Regarding external validity, a user testing procedure centered around "purposeful gaming" (also known as "wargaming" and "role playing games" in certain fields) is being developed. This will involve teams of decision-makers from the specific case study exploring a situation with the integrated model and using it to inform decision-making. For both of these, effort is already underway and future work is planned.

These case studies are partially useful because a standard is difficult to specify in a vacuum. As stated earlier, a major goal of the ongoing work on both the Benin water hyacinth case and the Rio de Janeiro mangrove forest case is to lay the groundwork for such a generalized EnvironmentVulnerability-Decision-Technology Model standard and library. For this reason, additional case studies are desired and work is underway to identify them. A case study is effective when it is tenable to modeling, it can be examined with the four proposed questions, and there is a partner who is interested in collaborating with the team to help ensure that locally derived insight and data drives the integrated model design. With each subsequent case study, the library of submodels will grow and the necessary elements of an interface standard will be made more clear. In this way, it is our hope that in addition to providing a real benefit to the residents of the Lake Nokoué and Rio de Janeiro region, we take steps towards providing generalized tools for other groups to use in other parts of the world, be it monitoring water hyacinth in China or hydrilla in Austin, Texas.

\section{ACKNOWLEDGMENTS}

The authors thank Dr. Fohla Mouftaou and the team from Green Keeper Africa for serving as collaborators on the water hyacinth case study. The authors acknowledge the work of Anisha Nakagawa, Ilham Ali, Xuenan Ni, Juan Carlos Garcia, Ufuoma Ovienmhada, Aliza Camacho, TojumiOluwa Adegboyega on the Benin case study. We thank Planet for sharing their satellite data with researchers. We thank Felipe Mandarino and colleagues from the city government of Rio de Janeiro for guidance. We have also learned from conversations with Dr. Temilola Fatoyinbo, Helen Greatrex, Andrew Kruczkiewicz, Chia-Ying Lee, and Kyle Mandli. 


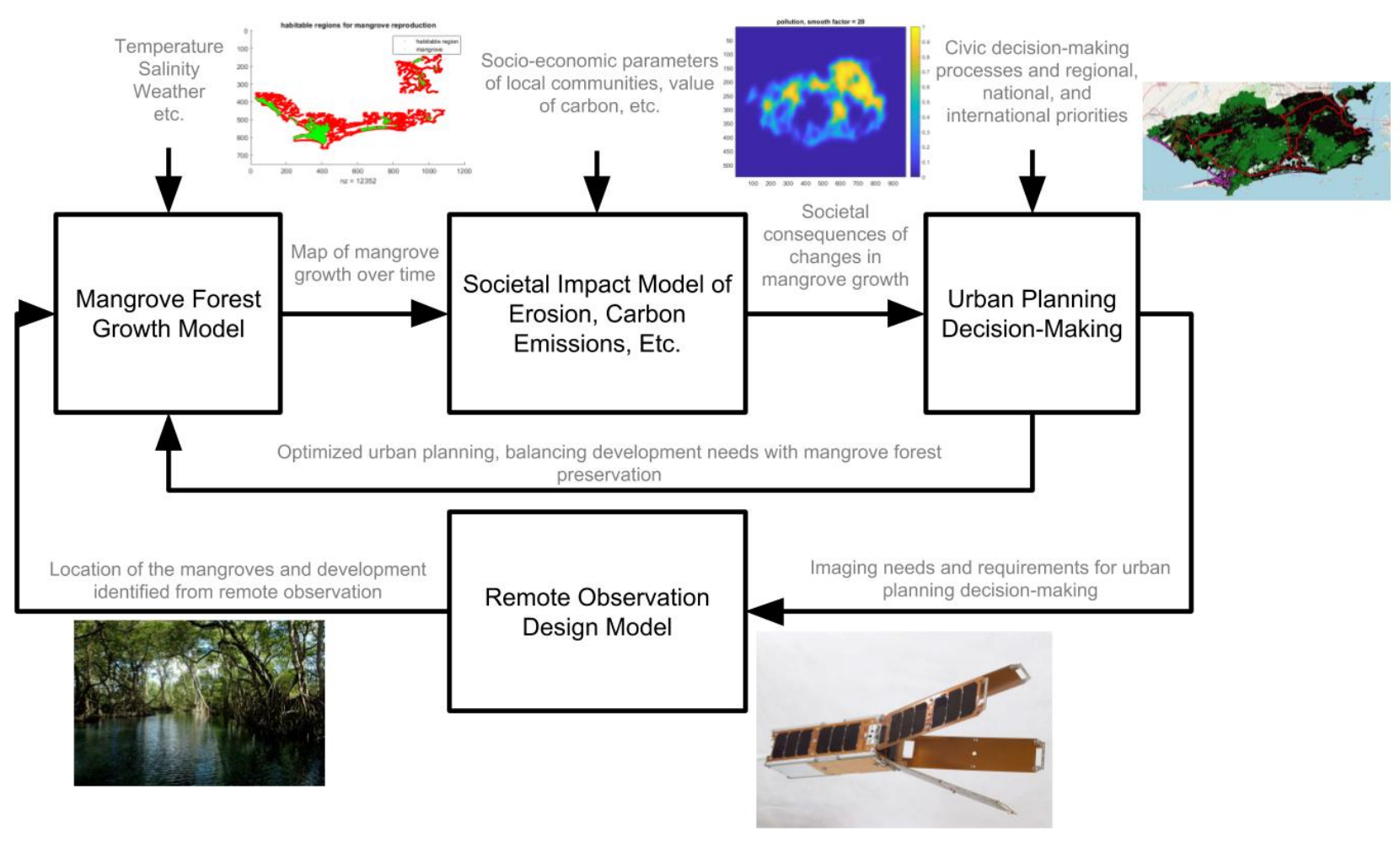

Figure 6. Environment - Vulnerability - Decision - Technology Model (Mangrove Forest Case)

\section{REFERENCES}

[1] O. L. De Weck, A. M. Ross, and D. H. Rhodes, "ESD Working Paper Series Investigating Relationships and Semantic Sets amongst System Lifecycle Properties (Ilities)," 2012. [Online]. Available: http://www. engineeringvillage.com

[2] J. Sachs, The Age of Sustainable Development. Columbia University Press, 2015.

[3] World Commission on Environment and Development, "Our Common Future," 1987. [Online]. Available: http://www.un-documents.net/our-common-future.pdf

[4] D. Meadows, D. Meadows, J. Randgers, and W. Behrens, The Limits to Growth. Washington D.C.: Potomac Associates, 1972.

[5] Inter-Agency and Expert Group on MDG Indicators, "The Millennium Development Goals Report," 2015. [Online]. Available: http://www.un.org/millenniumgoals/2015_MDG_ Report/pdf/MDG2015rev(July1).pdf

[6] United Nations, "Transforming Our World: The 2030 Agenda for Sustainable Development," 2015. [Online]. Available: https: //sustainabledevelopment.un.org/content/documents/ 21252030AgendaforSustainableDevelopmentweb.pdf

[7] United Nations General Assembly, "Global indicator framework for the Sustainable Development Goals and targets of the 2030 Agenda for Sustainable Development," 2017.

[8] G. Shirah, "NASA's Earth Observing Fleet: March 2017," 2017. [Online]. Available: https://svs.gsfc.nasa. gov/4558

[9] M. Borowitz, Open space : the global effort for open access to environmental satellite data. Cambridge, MA: MIT Press, 2017. [Online]. Available: https://mitpress.mit.edu/books/open-space

[10] M. M. Waldrop, "Landsat commercialization stumbles again." Science (New York, N.Y.), vol. 235, no. 4785, p. 155, 1 1987. [Online]. Available: http: //www.ncbi.nlm.nih.gov/pubmed/17778620

[11] G. Popkin, "US government considers charging for popular Earth-observing data," Nature, vol. 556, no. 7702, pp. 417-418, 4 2018. [Online]. Available: http://www.nature.com/articles/d41586-018-04874-y

[12] F. Tepper, "Satellite Maker Planet Labs Acquires BlackBridge's Geospatial Business," San Francisco, CA, 7 2015. [Online]. Available: https://techcrunch.com/2015/07/15/satellite-makerplanet-labs-acquires-blackbridges-geospatial-business/

[13] J. Shieber and I. Lunden, "Astro Digital launched its first imaging satellites," San Francisco, CA, 72017. [Online]. Available: https://techcrunch.com/2017/07/ 14/astro-digital-launched-its-first-imaging-satellites/

[14] W. Schroeder, P. Oliva, L. Giglio, and I. A. Csiszar, "The New VIIRS $375 \mathrm{~m}$ active fire detection data product: Algorithm description and initial assessment," Remote Sensing of Environment, vol. 143, pp. 85-96, 2014. [Online]. Available: http: //dx.doi.org/10.1016/j.rse.2013.12.008

[15] A. Y. Hou, R. K. Kakar, S. Neeck, A. A. Azarbarzin, C. D. Kummerow, M. Kojima, R. Oki, K. Nakamura, and T. Iguchi, "The global precipitation measurement 
mission," Bulletin of the American Meteorological Society, vol. 95, no. 5, pp. 701-722, 2014.

[16] J. Wahr, S. Swenson, V. Zlotnicki, and I. Velicogna, "Time-variable gravity from GRACE: First results," Geophysical Research Letters, vol. 31, no. 11, pp. 2023, 2004.

[17] M. Mcgill, T. Markus, S. S. Scott, and T. Neumann, "The multiple altimeter beam experimental lidar (MABEL): An airborne simulator for the ICESat-2 mission," Journal of Atmospheric and Oceanic Technology, vol. 30, no. 2, pp. 345-352, 2013.

[18] S. Biancamaria, D. P. Lettenmaier, and T. M. Pavelsky, "The SWOT Mission and Its Capabilities for Land Hydrology," Surveys in Geophysics, vol. 37, no. 2, pp. 307-337, 2016.

[19] NASA Jet Propulsion Laboratory, "Satellite Radar Detects Damage from Sept. 19, 2017 Raboso, Mexico, Quake," 2017. [Online]. Available: https://www.jpl. nasa.gov/spaceimages/details.php?id=pia21963

[20] _ _ "Satellite Data of Puerto Rico Identifies Possible Damage Areas - NASA Disaster Response," 2017. [Online]. Available: https://blogs.nasa.gov/disasterresponse/2017/09/27/satellite-data-of-puerto-ricoidentifies-possible-damage-areas/

[21] M. Finer, S. Novoa, M. J. Weisse, R. Petersen, J. Mascaro, T. Souto, F. Stearns, and R. G. Martinez, "Combating deforestation: From satellite to intervention," Science, vol. 6395, no. 360, pp. 1303-1305, 2018.

[22] J. S. Agte, N. K. Borer, and O. De Weck, "A Simulation-based Design Model for Analysis and Optimization of Multi-State Aircraft Performance," in 51st AIAA/ASME/ASCE/AHS/ASC Structures, Structural Dynamics, and Materials Conference. Orlando, FL: AIAA, 2010. [Online]. Available: http://strategic.mit.edu/docs/3_126-AIAA2010-2997-Multi-State-Aircraft.pdf

[23] I. Ferreira, O. de Weck, P. Saraiva, J. Cabral, I. Ferreira, O. de Weck, P. Saraiva, and J. Cabral, "Multidisciplinary optimization of injection molding systems," Structural and Multidisciplinary Optimization, vol. 41, pp. 621-635, 2010. [Online]. Available: http://strategic.mit.edu/docs/2_31_SMO_ 41_621_635_Injection_Molding.pdf

[24] O. de Weck, J. Agte, J. Sobieszczanski-Sobieski, P. Arendsen, A. Morris, and M. Spieck, "State-ofthe-Art and Future Trends in Multidisciplinary Design Optimization," in Structures, Structural Dynamics, and Materials Conference. Honolulu, HI: American Institute of Aeronautics and Astronautics, 2007. [Online]. Available: http://www.cranfield.ac.uk/soe/ structureshttp://arc.aiaa.org\%7C

[25] T. D. West and A. Pyster, "Untangling the Digital Thread: The Challenge and Promise of ModelBased Engineering in Defense Acquisition," INSIGHT, vol. 18, no. 2, pp. 45-55, 2015. [Online]. Available: http://dx.doi.org/10.1002/inst.12022

[26] E. J. Tuegel, A. R. Ingraffea, T. G. Eason, and S. M. Spottswood, "Reengineering Aircraft Structural Life Prediction Using a Digital Twin," International Journal of Aerospace Engineering, vol. 2011, 2011. [Online]. Available: http://dx.doi.org/10.1155/2011/154798

[27] A. Falcone, A. Garro, S. Taylor, A. Anagnostou, N. R. Chaudhry, and O. Salah, "Experiences in simplifying distributed simulation: The HLA development kit framework," Journal of Simulation, vol. 11, no. 3, pp. 208-227, 2017. [Online]. Available: http://www.pitch. sel

[28] M. K. Macauley, “The value of information: Measuring the contribution of space-derived earth science data to resource management," Space Policy, vol. 22, no. 4, pp. 274-282, 2006.

[29] R. Cooke, A. Golub, B. A. Wielicki, D. F. Young, M. G. Mlynczak, and R. R. Baize, "Using the social cost of carbon to value earth observing systems," Climate Policy, vol. 3062, no. January, pp. 1-16, 2016. [Online]. Available: http://www.tandfonline.com/doi/ full/10.1080/14693062.2015.1110109

[30] W. M. Forney, R. P. Raunikar, R. L. Bernkopf, and S. K. Mishra, "An Economic Value of RemoteSensing Information - Application to Agricultural Production and Maintaining Groundwater Quality," U.S. Geological Survey Professional Paper, no. 1796, 2012. [Online]. Available: http://pubs.usgs.gov/pp/ 1796/pp1796.pdf

[31] J. Kruse, J. Crompvoets, and F. Pearlman, Eds., GEOValue: The Socioeconomic Value of Geospatial Information. New York, NY: CRC Press, 2018.

[32] G. Flato, J. Marotzke, B. Abiodun, P. Braconnot, S. C. Chou, W. Collins, P. Cox, F. Driouech, S. Emori, V. Eyring, C. Forest, P. Gleckler, E. Guilyardi, C. Jakob, V. Kattsov, C. Reason, and M. Rummukainen, "Evaluation of Climate Models," in Climate Change 2013: The Physical Science Basis. Cambridge, UK: Cambridge University Press, 2013, ch. 9, pp. 741-867.

[33] R. Hakimdavar, D. Wood, J. Eylander, C. PetersLidard, J. Smith, B. Doorn, D. Green, C. Hummel, and T. C. Moore, "Transboundary Water: Improving Methodologies and Developing Integrated Tools to Support Water Security," Greenbelt, MD, 2018. [Online]. Available: http://www.sti.nasa.gov

[34] K. D. Cheramie, "The Scale of Nature: Modeling the Mississippi River,” Places Journal, no. 2011, 32011. [Online]. Available: https://placesjournal.org/article/ the-scale-of-nature-modeling-the-mississippi-river/

[35] P. Dragicevic, “1889 - Gaudí’s Hanging Chain Models," 2015. [Online]. Available: http://dataphys. org/list/gaudis-hanging-chain-models/

[36] W. Kron, "Flood Risk = Hazard • Values • Vulnerability," Water International, vol. 30, no. 1, pp. 58-68, 2005. [Online]. Available: http://www.tandfonline.com/ action/journalInformation?journalCode=rwin20

[37] S. Cutter and C. Emrich, "Moral Hazard, Social Catastrophe: The Changing Face of Vulnerability along the Hurricane Coasts," The Annals of the American Academy of Political and Social Science, vol. 604, no. 1, pp. 102-112, 2006. [Online]. Available: http://journals. sagepub.com/doi/pdf/10.1177/0002716205285515

[38] S. Zahran, S. D. Brody, W. G. Peacock, A. Vedlitz, and H. Grover, "Social vulnerability and the natural and built environment: A model of flood casualties in Texas," Disasters, vol. 32, no. 4, pp. 537-560, 2008.

[39] S. Bassett, "Methods," in Greater Santa Fe Fireshed Coalition Wildfire Risk Assessment, 1st ed. Sante Fe, NM: The Nature Conservancy, 2018. [Online]. Available: https://static1. squarespace.com/static/57b62cb1ebbd1a48387a40ef/t/ 
5b0d8e6d6d2a73fa9a91226b/1527615136172/GSFFC_ WildfireRiskAssessment_FullReport.pdf

[40] Congressional Budget Office, "An Overview of CBO's Microsimulation Tax Model," Washington D.C., 2018. [Online]. Available: https://www.cbo.gov/system/files? file $=2018-06 / 54096$-taxmodel.pdf

[41] S. Pennings, "Long Term Growth Model (LTGM v4.1)-Model Description," 2018. [Online]. Available: http://pubdocs.worldbank.org/en/ 887381517952394875/Model-Outline-V4-1.pdf

[42] M. Radzicki and J. Sterman, "Evolutionary Economics and System Dynamics," in Evolutionary Concepts in Contemporary Economics, R. England, Ed. Ann Arbor, MI: University of Michigan Press, 1994, pp. 61-81. [Online]. Available: https://books.google.com/books?hl=en\&lr=\&id= QDACUmOO8SsC\&oi=fnd\&pg=PA61\&dq=system+ dynamics+economics\&ots=E9wPEVoUEv\&sig= r67CzdkkIs9ojAuaVQQoH04LWzE\#v=onepage\&q= systemdynamicseconomics\& $\mathrm{f}=$ false

[43] S. K. C. Chai, M. F. Bin Zainal Abiden, H. M. Ng, S. Thian, S. Tio, S. Landry, and A. Fagette, "Using Social Sciences to Enhance the Realism of Simulation for Complex Urban Environments," in Complex Systems Design \& Management Asia. Singapore: Springer, Cham, 2016, pp. 235-246. [Online]. Available: http: //link.springer.com/10.1007/978-3-319-29643-2_18

[44] N. Pelechano and A. Malkawi, "Evacuation simulation models: Challenges in modeling high rise building evacuation with cellular automata approaches," Automation in Construction, vol. 17, no. 4, pp. 377-385, 5 2008. [Online]. Available: https://www.sciencedirect. com/science/article/pii/S0926580507000908

[45] R. White and G. Engelen, "Cellular Automata and Fractal Urban Form: A Cellular Modelling Approach to the Evolution of Urban Land-Use Patterns," Environment and Planning A: Economy and Space, vol. 25, no. 8, pp. 1175-1199, 81993. [Online]. Available: http://journals.sagepub.com/doi/ 10.1068/a251175

[46] G. Brown, M. Carlyle, D. Diehl, J. Kline, and K. Wood, "A Two-Sided Optimization for Theater Ballistic Missile Defense," Operations Research, vol. 53, no. 5, pp. 745-763, 2005. [Online]. Available: http://pubsonline.informs.org/doi/abs/10. 1287/opre.1050.0231

[47] A. Chuang, F. Wu, and P. Varaiya, "A gametheoretic model for generation expansion planning: problem formulation and numerical comparisons," IEEE Transactions on Power Systems, vol. 16, no. 4, pp. 885-891, 2001. [Online]. Available: http://ieeexplore.ieee.org/document/962441/

[48] S. Lauf, D. Haase, P. Hostert, T. Lakes, and B. Kleinschmit, "Uncovering land-use dynamics driven by human decision-making - A combined model approach using cellular automata and system dynamics," Environmental Modelling \& Software, vol. 27-28, pp. 71-82, 12012. [Online]. Available: https://www.sciencedirect.com/ science/article/pii/S1364815211002039

[49] M. Masutani, T. W. Schlatter, R. M. Errico, A. Stoffelen, E. Andersson, W. Lahoz, J. S. Woollen, G. D. Emmitt, L.-P. Riishojgaard, and S. J. Lord, "Observing System Simulation Experiments," in Data Assimilation:
Making Sense of Observations. New York City, NY: Springer, 2010, ch. VI.2, pp. 647-679.

[50] R. M. Errico, R. Yang, N. C. Privé, K. S. Tai, R. Todling, M. E. Sienkiewicz, and J. Guo, "Development and validation of observing-system simulation experiments at NASA's global modeling and assimilation office," Quarterly Journal of the Royal Meteorological Society, vol. 139, no. 674, pp. 1162-1178, 2013.

[51] S. V. Kumar, C. D. Peters-Lidard, Y. Tian, P. R. Houser, J. Geiger, S. Olden, L. Lighty, J. L. Eastman, B. Doty, P. Dirmeyer, J. Adams, K. Mitchell, E. F. Wood, and J. Sheffield, "Land information system: An interoperable framework for high resolution land surface modeling," Environmental Modelling and Software, vol. 21, no. 10, pp. 1402-1415, 2006.

[52] R. Lobel and G. Perakis, "Consumer Choice Model For Forecasting Demand And Designing Incentives For Solar Technology," Cambridge, MA, 2011. [Online]. Available: http://citeseerx.ist.psu.edu/viewdoc/ download?doi=10.1.1.188.1739\&rep=rep1\&type=pdf

[53] J. Morris, M. Webster, J. Reilly, R. G. Prinn, and J. M. Reilly, "Electricity Generation and Emissions Reduction Decisions under Policy Uncertainty: A General Equilibrium Analysis," Cambridge, MA, 2014. [Online]. Available: https://globalchange.mit.edu/sites/ default/files/MITJPSPGC_Rpt260.pdf

[54] C. Martani, D. Lee, P. Robinson, R. Britter, and C. Ratti, "ENERNET: Studying the dynamic relationship between building occupancy and energy consumption," Energy and Buildings, vol. 47, pp. 584-591, 42012. [Online]. Available: https://www.sciencedirect.com/ science/article/pii/S0378778811006566

[55] Z. A. Needell and J. E. Trancik, "Efficiently Simulating Personal Vehicle Energy Consumption in Mesoscopic Transport Models," in Transportation Research Board 97th Annual Meeting, Washington D.C., 2018. [Online]. Available: https://trid.trb.org/view/1496897

[56] C. L. Azevedo, R. Seshadri, S. Gao, B. Atasoy, A. P. Akkinepally, E. Christofa, F. Zhao, J. Trancik, and M. Ben-Akiva, "Tripod: Sustainable Travel Incentives with Prediction, Optimization, and Personalization," in Transportation Research Board 97th Annual Meeting. Washington D.C.: Transportation Research Board, 2018. [Online]. Available: https://trid.trb.org/view/ 1497430

[57] D. Wood, "Partnerships to enable earth science applications," in 68th International Astronautical Congress. Adelaide, Australia: IAF, 2017, pp. 25-29.

[58] NASA Applied Sciences Program, "The Application Readiness Level Metric." [Online]. Available: https://www.nasa.gov/sites/default/files/ files/ExpandedARLDefinitions4813.pdf

[59] M. Julien, M. Hill, T. Center, and D. Jianqing, "Biological and Integrated Control of Water Hyacinth , Eichhornia crassipes," in Proceedings of the Second Meeting of the Global Working Group for the biological and Integrated Control of Water Hyacinth, vol. 102. Beijing, China: Australian Centre for International Agricultural Research, 2000.

[60] M. B. Djihouessi, M. B. Djihouessi, and M. P. Aina, "A review of habitat and biodiversity research in Lake Nokoué, Benin Republic: Current state of knowledge and prospects for further research," Ecohydrology and 
Hydrobiology, pp. 1-15, 2018. [Online]. Available: https://doi.org/10.1016/j.ecohyd.2018.04.003

[61] Green Keeper Africa, "About Us," 2014. [Online]. Available: http://greenkeeperafrica.com/green-keeperafrica/?lang=en

[62] R. Verma, "Assessment of changes in water- hyacinth coverage of water bodies in northern part of Bangalore city using temporal remote sensing data," Current Science, vol. 84, no. 6, pp. 795-804, 2003.

[63] S. S. Rajapakse, S. Khanna, M. E. Andrew, S. L. Ustin, and M. Lay, "Identifying and classifying water hyacinth (Eichhornia crassipes) using the HyMap sensor," in Proceedings of SPIE, vol. 6298, 2006. [Online]. Available: http://proceedings.spiedigitallibrary.org/ proceeding. asp $\mathrm{x}$ ?articleid $=1329073$

[64] K. B. Gedan, M. L. Kirwan, E. Wolanski, E. B. Barbier, and B. R. Silliman, "The present and future role of coastal wetland vegetation in protecting shorelines: answering recent challenges to the paradigm," Climatic Change, vol. 106, no. 1, pp. 7-29, 2011.

[65] P. Rönnbäck, "The ecological basis for economic value of seafood production supported by mangrove ecosystems," Ecological Economics, vol. 29, no. 2, pp. 235$252,1999$.

[66] E. L. Gilman, J. Ellison, N. C. Duke, and C. Field, "Threats to mangroves from climate change and adaptation options: a review," Aquatic botany, vol. 89, no. 2, pp. 237-250, 2008.

[67] Lacerda, Luiz and Menezes, Marcelo and Mussi Molisani, Maurício, "Changes in mangrove extension at the Pacoti River estuary, CE, NE Brazil due to regional environmental changes between 1958 and 2004," Biota Neotropica, vol. 7, pp. 1-7, 2007.

[68] I. Sussex, "Growth and metabolism of the embryo and attached seedling of the viviparous mangrove, Rhizophora mangle," American Journal of Botany, vol. 62, no. 9, pp. 948-953, 1975.

[69] C. P. Herzog and R. Finotti, "Local Assessment of Rio de Janeiro City: Two Case Studies of Urbanization Trends and Ecological Impacts," in Urbanization, Biodiversity and Ecosystem Services: Challenges and Opportunities. Springer, 2013, pp. 609-628.

[70] E. Winsberg, Science in the Age of Computer Simulation. University of Chicago Press, 2010. [Online]. Available: http://www.bibliovault.org/BV. landing.epl?ISBN=9780226902043

[71] J. R. Bursten, "Surfaces, Scales, and Synthesis: Scientific Reasoning at Nanoscale," Ph.D. dissertation, University of Pittsburgh, 2015.

\section{BIOGRAPHY}

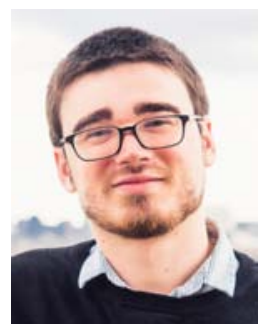

Jack Reid received his $B S$ in mechanical engineering and BA in philosophy from Texas A\&M University in 2015; a SM. in Aeronautics \& Astronautics and a SM in Technology \& Policy from the Massachusetts Institute of Technology in 2018. He is currently a doctoral student at MIT. His research focuses on complex sociotechnical system modeling.

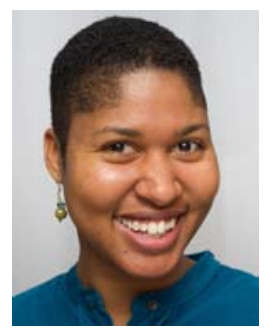

Danielle Wood is an assistant professor in the Program in Media Arts and Sciences at MIT. She received a PhD in engineering systems (2012), SM in aeronautics and astronautics (2008), SM in technology policy (2008), and SB in aerospace engineering (2005) from MIT. Prof. Wood has previously worked as the Applied Sciences Manager within the Earth Science Division of Goddard Space Flight Center and as Special Assistant and Advisor to the Deputy Administrator at NASA Headquarters in Washington, DC. Prior to working at NASA, Prof. Wood held positions at the Aerospace Corporation, Johns Hopkins University, and the United Nations Office of Outer Space Affairs. Her primary research interests are in societal development via satellite design, earth science applications, systems engineering, technology policy for the US and emerging nations, and the development of systems analysis tools to improve decision making. Prof. Wood leads the Space Enabled Research Group which seeks to advance justice in earth's complex systems using designs enabled by space.

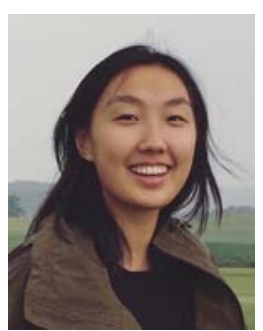

Cynthia Zeng received her BS in mathematics from Imperial College London in 2017. She completed a summer internship at the Space Enabled group on the topic of complex systems modeling for mangrove forests in 2018. She is a prospective graduate student. 